\title{
Analysis of the Bearing Characteristics of Single Piles under Vertical and Torsional Combined Loads
}

\author{
Shun-Wei Wang $\mathbb{D}^{1,2,3}$ Jie Jiang $\mathbb{D}^{1,2,3}$ Chen-Zhi Fu, ${ }^{1,2,3}$ Xiao-Duo Ou $\mathbb{D}^{1,2,3}$ and Juan Tang ${ }^{1,2,3}$ \\ ${ }^{1}$ College of Civil Engineering and Architecture, Guangxi University, Nanning 530004, China \\ ${ }^{2}$ Key Laboratory of Disaster Prevention and Structural Safety of Ministry of Education, Guangxi University, \\ Nanning 530004, China \\ ${ }^{3}$ Guangxi Key Laboratory of Disaster Prevention and Engineering Safety, Guangxi University, Nanning 530004, China
}

Correspondence should be addressed to Jie Jiang; jie_jiang001@126.com

Received 28 June 2020; Revised 21 September 2020; Accepted 25 January 2021; Published 28 February 2021

Academic Editor: Valeria Vignali

Copyright (c) 2021 Shun-Wei Wang et al. This is an open access article distributed under the Creative Commons Attribution License, which permits unrestricted use, distribution, and reproduction in any medium, provided the original work is properly cited.

\begin{abstract}
To investigate the bearing characteristics of single piles under the combined action of vertical loads $(V)$ and torque $(T)$ on a pile head, the displacement governing equations of the pile shaft were proposed in consideration of the load transfer method, and the nonlinear solution of a single-loaded pile (vertical load or torque) was calculated by the finite difference method. According to the above mentioned investigation, a new numerical analysis model was proposed to modify the vertical and circumferential ultimate friction resistance of the pile side. Subsequently, the nonlinear solutions of single piles under the combined loads of $V$ - $T$ loading with different loading paths were obtained by MATLAB programming, and the bearing capacity envelopes were plotted. Based on the comparison with the existing research results, the correctness of the theoretical calculation method proposed in this article was verified. The results show that compared with a single loaded pile ( $V$ or $T)$, with the action of the $V$ - $T$ combined loads, the bearing capacity of a single pile will decrease, and the single piles under the $V \longrightarrow T$ loading path will have a higher bearing capacity than those under the $T \longrightarrow V$ loading path. When the aspect ratio is comparatively small, the influence of the loading path is negligible; however, when the aspect ratio is comparatively large, it is necessary to avoid the preliminary application of the torque to a single pile to prevent the decrease in the ultimate bearing capacity on account of the formation of the $T \longrightarrow V$ loading mode. The deformation of the pile body mainly occurs in the range from 0 to $0.6 \mathrm{~L}$, so effective deformation reduction can be achieved by reinforcing the shallow foundation. It is inadvisable for a single friction pile to be used to improve the bearing capacity by increasing the concrete grade.
\end{abstract}

\section{Introduction}

To ensure the safety of buildings (structures), pile foundations are often used in actual projects. Large infrastructure pile foundations, such as high-rise buildings, urban overpasses, and onshore wind power systems, will bear not only vertical loads $(V)$ but also large torque $(T)$ due to horizontal eccentric loads, lateral impact loads, and earthquakes. The conventional pile foundation design method merely considers a single vertical load and ignores the effect of torsional loading, which may cause substantial engineering losses in serious cases [1]. Therefore, research on the bearing characteristics of the $V-T$ combined loaded pile is of great importance for the formulation of a reasonable engineering scheme.

Currently, the study on the bearing and deformation characteristics of single piles under a single vertical or torsional load has been relatively established by scholars. For a single vertically loaded pile, Seed and Reese [2] studied the load transfer mechanism at the pile-soil interface and the load transfer method was first proposed. Since then, several scholars have carried out a series of in-depth studies. Zhang et al. [3] utilized a hyperbolic curve model to explain the lateral friction of single piles and a polyline model to simulate the hardening of the pile tip. Based on this, an elastoplastic solution for single piles in layered soil was 
proposed. Based on the load transfer method and the shear displacement method, the elastoplastic solution of single piles in a heterogeneous foundation was obtained by Jiang et al. [4]. For pure torsion piles, Poulos [5] and Randolph [6] solved the relationship between the pile top torque and torsion angle in accordance with the theory of elastic continuous media, and it was verified by experiments. Chen and Zhang [7] adopted the method of integral transformation and transfer matrix, considered the pile-soil displacement coordination conditions, and proposed a semianalytical method for torsional deformation on single piles in layered soils; Li and Armin [8] used existing experimental data to establish a load transfer model and the nonlinear calculation method for the torsional loaded piles was successfully obtained by adopting the finite difference method. Basack and Sen [9] considered the nonlinear change of the soil shear moduli with increasing depth, and the numerical solution of pile torsion was obtained by using the boundary element method. In addition, the force analysis of the pile in layered soils was finished.

For the $V$-T combination-loaded pile, Georgiadis and Saflekou $[10,11]$ regarded the pile as an elastic rod and used independent nonlinear axial and torsion springs to describe the mechanical behaviours of the pile-soil interface, however, this study did not take the inconsistency of the pile-soil interface displacement into consideration, which gave rise to a difference in the results. Fan and Meng [12] utilized ABAQUS software to gain the ultimate bearing capacity envelope of pipe piles with a relatively small length-diameter ratio under the combination of $V$ - $T$ loading, however, this behaviour is extremely complex to the model and requires substantial computational time. Militano and Rajapakse [13] conducted a dynamic analysis in the Laplace transform domain for a pile in multilayered soil under transient torsional and axial loading based on the simplified continuum model. The above-mentioned methods did not consider the effect of loading paths on bearing capacity of single pile; to explore the effect of loading paths, Zou et al. [14, 15] assumed that the soil was a Gibson foundation; with the depth of the plastic zone as a variable, the elastoplastic solution of the single pile under the combination of $V$-T loading was obtained, which laid the foundation for the further study of the combined pile of $V$-T loading, however, it was not easy to determine the value of the calculation parameter, that is, difficult to promote in the engineering design. In general, research on the $V$-T combined loaded piles is still relatively limited, especially on the effect of loading paths.

In this study, the effects of different $V-T$ load combinations and loading paths were taken into account, and a new numerical analysis model was proposed. Firstly, considering the inconsistency of the displacement on the pilesoil interface, the load transfer function was introduced, and the pile displacement control equation was established to obtain the pile side friction and load-displacement response of a single loaded pile ( $V$ or $T$ ). Subsequently, the ultimate friction resistance of the pile body under different loading paths was modified, and the pile displacement solution and the pile bearing capacity envelope was obtained under different loading paths $(V \longrightarrow T$ or $T \longrightarrow V)$. Finally, the main influencing parameters of the pile bearing performance under the combined action of $V-T$ were discussed, and engineering control measures were proposed.

\section{Nonlinear Calculation Method of $V$-T Combined Loaded Piles considering Loading Path Variation}

2.1. Determination of the Ultimate Friction on the Pile Side. As shown in Figure 1(a), to obtain the nonlinear solution of single piles under the combination of $V$-T loading, the pile is separated into $n$ elements of length $L / n$. Under the combination of $V$-T loading, the soil friction resistance acts on the surface of the pile body, and the friction resistance of each unit can be decomposed into vertical friction resistance $\tau_{v}(i)$ and circumferential friction resistance $\tau_{t}(i)$. Since the failure of the pile-soil interface of single piles under the combination of $V$ - $T$ loading is shear failure, it can be assumed that the vertical and hoop ultimate frictional resistance of the element should meet the requirements of the shear element model of the pile-soil interface, as shown in Figure 1(b). Then, the total frictional resistance of the pilesoil interface of the $i$-th unit should satisfy the following equilibrium condition:

$$
\tau_{i}=\sqrt{\left[\tau_{t}(i)\right]^{2}+\left[\tau_{v}(i)\right]^{2}} \leq \tau_{f}(i)
$$

The ultimate friction force at the pile-soil interface is expressed as

$$
\tau_{f}(z)=k_{0} \gamma z \tan \varphi^{\prime}+c
$$

where $k_{0}$ is the coefficient of the active Earth pressure, $\gamma$ is the gravity of the soil, $c$ is the cohesion, and $\varphi^{\prime}$ is the friction angle of the pile-soil interface. The value of $\varphi^{\prime}$ is equal to $0.6 \sim 0.9 \varphi$ according to different soil properties [16], where $\varphi$ is the effective internal friction angle of the soil. It should be noted that, for saturated clay, $\tau_{f}$ is equal to the undrained shear strength of the soil [17], and for sand, the value of $c$ is equal to 0 .

Preloading the pile top will inevitably change the side friction of the pile. For instance, under the $T \longrightarrow V$ loading path, the existence of circumferential friction at the pile-soil interface will inevitably cause a decrease in the vertical ultimate friction. For single piles under the $T \longrightarrow V$ loading path, the hoop friction resistance under the action of torque can be calculated first, and the vertical ultimate friction resistance can be determined by the following formula:

$$
\tau_{v f}(i)=\sqrt{\left[\tau_{f}(i)\right]^{2}-\left[\tau_{t}(i)\right]^{2}}
$$

Similarly, under the $V \longrightarrow T$ loading path, the vertical frictional resistance under the vertical load can be calculated first, and the circumferential ultimate frictional resistance of the single pile can be determined by the following formula:

$$
\tau_{t f}(i)=\sqrt{\left[\tau_{f}(i)\right]^{2}-\left[\tau_{v}(i)\right]^{2}}
$$




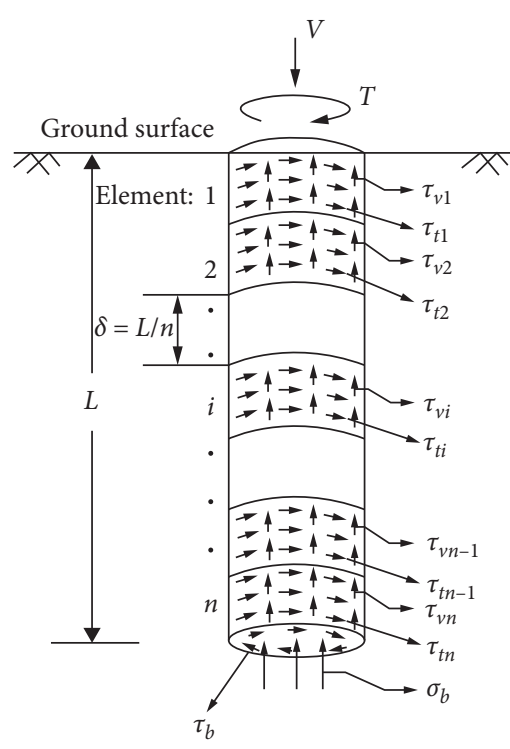

(a)

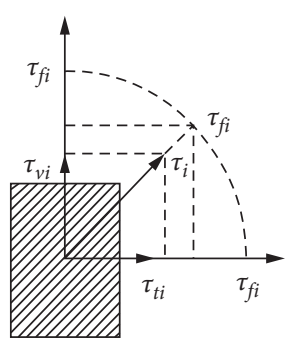

(b)

Figure 1: Shear effect of the soil around the pile shaft. (a) Discrete diagram of a single pile. (b) Shear element model.

The number of pile units $(n)$ is increased from 5 to 1000 for sensitivity analysis. A large number of calculations show that when the value of $n$ exceeds 120 , more computer resources are required and the computational accuracy has not improved significantly. Therefore, analyses are conducted with $n=120$.

2.2. Solution under a Single Vertical Load. The pile unit with length $\mathrm{d} z$ at depth $z$ was taken for analysis. Under the action of vertical loads and according to the static equilibrium condition, the following equation can be obtained [3]:

$$
\frac{d P(z)}{d z}=-U_{p} \tau_{v}(z)
$$

where $U_{p}$ is the perimeter of the pile shaft, $P(z)$ is the axial force of the single pile at any depth $z$, and $\tau_{v}(z)$ is the vertical frictional resistance of the pile side at depth $z$.

The elastic compression of the pile microunit is expressed as follows:

$$
d w(z)=-\frac{P(z) d z}{E_{P} A_{p}}
$$

where $w(z)$ is the vertical displacement of the pile body, $E_{p}$ is the elastic modulus, and $A_{p}$ is the cross-sectional area of the pile.

Solving equations (5) and (6) can obtain the vertical governing equation of the pile body as follows:

$$
\frac{d^{2} w(z)}{d z^{2}}-\frac{U_{p}}{E_{p} A_{p}} \tau_{v}(z)=0 .
$$

The load transfer function of the pile-soil interface adopts the function form proposed by Kraft et al. as follows [18]:

$$
\tau_{v}(z)=\frac{G_{s} w(z)}{r_{0} \ln \left(r_{m} / r_{0}-\psi / 1-\psi\right)}
$$

The expression of tangent stiffness of the soil on the pile side can be written as follows:

$$
k_{v}=\frac{U_{p} \tau_{v}(z)}{w(z)} .
$$

The initial tangent stiffness is as follows:

$$
k_{v}^{\prime}=\left.\frac{U_{p} \partial \tau(z)}{\partial w(z)}\right|_{w(z)=0}=\frac{2 \pi G_{s}}{\left.\ln \left(r_{m} / r_{0}\right)\right)},
$$

where $G_{s}$ is the initial shear modulus of the soil under a small strain; $\psi=\tau(z) R_{f} / \tau_{f}$, where $R_{f}$ is the stress-strain curve fitting constant, which can take $0.9 \sim 1.0 ; \tau_{f}$ is the ultimate frictional resistance on the side of the pile; $r_{0}$ is the radius of the section of the pile; and $r_{m}$ is the effective influence radius.

The governing equation of the pile is expressed as follows:

$$
\frac{d^{2} w(z)}{d z^{2}}-\lambda^{2} w(z)=0
$$

where $\lambda=\sqrt{k_{v} / E_{p} A_{p}}$.

The marginal conditions of the pile top and tip are as follows.

For the pile top, the displacement is expressed as follows:

$$
w(0)=w_{0},
$$

where $w_{0}$ is the known reloading displacement.

For the pile tip, the vertical bearing capacity can be written as

$$
P(l)=\frac{w(l)}{1 / K_{b z}+w(l) / q_{u l t}},
$$


where $w(l)$ is the vertical displacement of the pile tip and $K_{b z}$ is the initial stiffness of the soil at the pile tip. The initial stiffness can be determined by the following equation $[19,20]$ :

$$
K_{b z}=\frac{4 G_{s} r_{0}}{\left(1-v_{s}\right)}
$$

where $v_{s}$ is the Poisson's ratio of the soil. When the soil at the pile tip is sand, silt, or clay, the ultimate resistance of the pile tip $q_{\text {ult }}$ can be expressed as follows [21]:

$$
q_{u l t}=c N_{c}+q N_{q},
$$

where $N_{c}$ and $N_{q}$ are the dimensionless bearing capacity constants related to the internal friction angle, which can be determined by referring to the table, $c$ is the cohesion of the soil, and $q$ is the average vertical pressure on the side of the plane at pile tip, which can be obtained as follows:

$$
q=\frac{\left(1+2 k_{0}\right) \gamma L}{3} .
$$

As shown in Figure 2, the finite difference method is utilized to solve the pile, which divides the pile into $n$ equal parts along the length and adds a virtual equalization node $n+1$ to the bottom of the pile.

The governing equations and boundary conditions of the pile can be differentially discretized to form a system of equations, which is written as a matrix as follows:

$$
\left[K_{z}^{\prime}\right]\{w\}=\left\{F_{z}^{\prime}\right\}
$$

where $\{w\}$ is the vertical displacement vector generated along the pile node when single piles are subjected to vertical loads, $\{w\}=\left\{w_{0}, w_{2}, \ldots, w_{i}, \ldots, w_{n-1} \cdot w_{n}\right\}^{T} ;\left[K_{z}^{\prime}\right]$ is the vertical stiffness matrix of the pile; $\left\{F_{z}^{\prime}\right\}$ is the vertical load vector of the pile node.

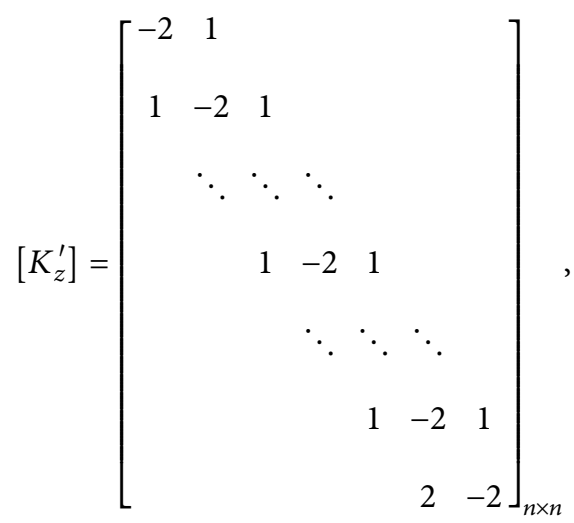

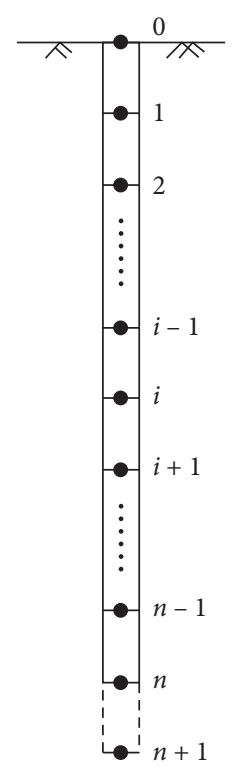

FIGURE 2: Diagrammatic sketch of differential dispersion of vertically loaded piles.

$$
\left\{F_{z}^{\prime}\right\}=\left\{\begin{array}{c}
\lambda_{1}^{\prime 2} h^{2} w_{1}-w_{0} \\
\lambda_{2}^{\prime 2} h^{2} w_{2} \\
\vdots \\
\lambda_{i}^{\prime 2} h^{2} w_{i} \\
\vdots \\
\lambda_{n-1}^{\prime 2} h^{2} w_{n-1} \\
\lambda_{n}^{\prime 2} h^{2} w_{n}+\frac{2 h\left(q_{u l t}+w_{n} K_{b z}\right)}{E_{p} A_{p} K_{b z} q_{u l t}} w_{n}
\end{array}\right\} .
$$

By solving formula (17), the vertical displacement along the pile body under vertical loading may be written as

$$
\{w\}=\left[K_{z}^{\prime}\right]^{-1}\left\{F_{z}^{\prime}\right\} .
$$

The solution process is as follows:

(i) Given an arbitrary nonzero matrix $\{w\},\{w\}$ can be set to be a random array between 0 and 1 .

(ii) Calculate tangent stiffness of the soil on the pile side, then the matrices $\left\{F_{z}^{\prime}\right\}$ and $\left\{K_{z}^{\prime}\right\}$ can be solved.

(iii) Place $\left\{F_{z}^{\prime}\right\}$ and $\left\{K_{z}^{\prime}\right\}$ back into equation (19), then the vertical displacement vector $\{w\}^{k}$ is obtained.

(iv) Based on the vertical displacement vector $\{w\}^{k}$, repeat steps (b) and (c), then the vertical displacement vector update to be $\{w\}^{k+1}$. 
(v) Set $\left|\{w\}^{k}-\{w\}^{k+1}\right|$ as iterative control value. If the value is greater than the specific tolerance, repeat steps (b) (d) until the value is less than the tolerance.

For the pile top load $P_{0}$, its magnitude is equal to the axial force of the second pile node as follows:

$$
P_{0}=E_{p} A_{p} \frac{w_{0}-w_{2}}{2 h} \text {. }
$$

2.3. Calculation of a Single Pile under Pure Torsional Loading. According to the force balance condition of the pile unit with length $d z$ under the action of torque, the equilibrium condition can be expressed as follows:

$$
\frac{d T(z)}{d z}=0.5 \pi \tau_{t}(z) D^{2}
$$

where $T(z)$ is the torque at depth $z, \tau_{t}(z)$ is the circumferential friction of the pile at depth $z$, and $D$ is the diameter of the pile.

Based on the deformation conditions of the pile element with a length of $d z$ under the action of torque, the equilibrium condition can be expressed as follows:

$$
\frac{d \theta(z)}{d z}=-\frac{T(z)}{J_{P} G_{P}},
$$

where $\theta(z)$ is the twist angle at depth $z, G_{p}$ is the shear modulus of the pile, and $J_{p}$ is the polar moment of inertia of pile section.

The twist angle of the pile body at any depth $z$ can be written as follows [8]:

$$
\theta(z)=\frac{2 s_{t}(z)}{D}
$$

Combining equations (21)-(23), the torsion governing equation of the pile can be obtained as follows:

$$
\frac{d \theta^{2}(z)}{d z^{2}}=\alpha^{2} \theta(z)
$$

where $\alpha=\sqrt{k_{\theta} \pi D^{3} / 4 G_{p} J_{p}}$, and the torsional tangent stiffness $k_{\theta}(z)$ can be expressed as follows:

$$
k_{\theta}(z)=\frac{\tau_{t}(z)}{s_{t}(z)},
$$

where $s_{t}(z)$ is the circumferential displacement for pile shaft at depth $z$.

The load transfer function of the pile-soil interface is given as follows.

$$
\tau_{t}(z)=\frac{G_{s} s_{t}(z)}{r_{0} \ln \left(r_{m} / r_{0}-\psi / 1-\psi\right)} .
$$
follows:

The marginal conditions of the pile top and tip are as

The pile top should satisfy the following equation:

$$
T(0)=T \text {. }
$$

For the pile tip, assuming that the torsion angle of the pile body is linearly distributed, and combining the boundary conditions of the pile tip proposed by Poulos [5], the equilibrium can be obtained as follows:

$$
\theta_{n}=\frac{\left(\theta_{n+1}+\theta_{n-1}\right)}{2}=\frac{3 T_{b}}{16 G_{L} r_{0}^{3}},
$$

where $G_{L}$ is the shear modulus of the soil at the bottom of the pile, and $T_{b}$ is the torque at the pile tip.

Solving equation (21), the torque at the bottom of the pile can be expressed as follows:

$$
T_{b}=T-\sum_{i=0}^{n-1} 0.5 \pi \tau_{t}(i) D^{2} h,
$$

where $T$ is the torque at the pile top.

To obtain the pile-side circumferential frictional resistance of each pile unit, as shown in Figure 3, the centre difference method is used to discretize the pile length into $n$ equal units, and a virtual equalization node is added at the top and tip of the pile. By substituting the boundary conditions into equation (24) for differential discretization, the following system of equations can be obtained as follows:

$$
\left[K_{t}^{\prime}\right]\{\theta\}=\left\{T_{t}^{\prime}\right\}
$$

where $\{\theta\}$ is the torsion angle vector of the pile node, $\{\theta\}=$ $\left\{\theta_{0} \theta_{1} \cdots \theta_{i} \cdots \theta_{n-1} \theta_{n}\right\}^{\mathrm{T}} ;\left\{T_{t}^{\prime}\right\}$ is the torsional load vector of the pile, where $\left\{T_{t}^{\prime}\right\}=\left\{-2 T h /\left(G_{p} J_{p}\right) \cdots 0 \cdots 0 \cdot \cdot 0 \cdot-3 T_{b} h /\left(8 G_{L} r_{0}^{3}\right)\right\}^{\mathrm{T}}$, and $\left[K_{t}^{\prime}\right]$ is the torsional stiffness matrix of the pile.

$$
\left[K_{t}^{\prime}\right]=\left[\begin{array}{ccccccc}
B_{0} & 2 & & & & & \\
1 & B_{1} & 1 & & & & \\
& \ddots & \ddots & \ddots & & & \\
& & 1 & B_{i} & 1 & & \\
& & & \ddots & \ddots & \ddots & \\
& & & & 1 & B_{n-1} & 1 \\
& & & & & & B_{n}
\end{array}\right]_{(n+1) \times(n+1)}
$$

where $B_{i}=-\left(\alpha_{i}^{2} h^{2}+2\right)$.

Solving equation (30) can provide the torsional angle along the pile body as follows:

$$
\{\theta\}=\left[K_{t}^{\prime}\right]^{-1}\left\{T_{t}^{\prime}\right\} .
$$

The solution process of equation (29) is as follows:

(i) Assuming that the torsion angle $\theta$ along the pile node is an arbitrary nonzero value.

(ii) The circumferential displacement $s_{t}(z)$ at depth $z$ is obtained from equation (23), then the matrices $\left\{T_{t}^{\prime}\right\}$ and $K_{t}^{\prime}$ can be solved.

(iii) Place $\left\{T_{t}^{\prime}\right\}$ and $K_{t}^{\prime}$ back into equation (19), then the $\theta^{k}$ at each node of the pile are obtained.

(iv) Based on $\theta^{k}$ along the pile node, repeat steps (b) and (c), then the torsion angle of the pile body update to be $\theta^{k+1}$. 


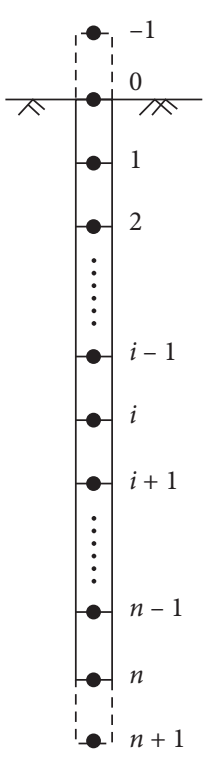

FIgURE 3: Schematic diagram of the differential dispersion of pure torsion piles.

(v) Set $\left|\theta^{k+1}-\theta^{k}\right|$ as iterative control value. If the value is greater than the specific tolerance, repeat steps (b) (d) until the value is less than the tolerance.

2.4. Solution Process. The solution process of $V$-T combined loaded piles under different loading paths is as follows. Taking the $V \longrightarrow T$ loading path as an example, the vertical displacement $w$ of a single vertical loaded pile can be obtained according to Section 2.2. Solving equation (8), the vertical frictional resistance of the pile body $\tau_{v}(i)$ is obtained. Subsequently, the ultimate circumferential frictional resistance of the pile side $\tau_{t f}(i)$ is easily obtained by solving equation (3). Finally, substituting $\tau_{t f}(i)$ into equation (26), the $T_{\theta}$ curve under the $V \longrightarrow T$ loading path can be achieved by the method in Section 2.3. Moreover, the similar method can be used to obtain the $V$-s curve under the $T \longrightarrow V$ loading path.

2.5. Bearing Capacity Envelope under Different Loading Paths. The drawing method of the single pile bearing capacity envelope under different loading paths is as follows: taking the $V \longrightarrow T$ loading path as an example, the $T-\theta_{t}$ curves corresponding to different vertical loads $V_{i}$ is obtained according to the method in Section 2.4, the torque $T_{u i}$ corresponding to the reverse bending point of the curve is the limit torque under the $V \longrightarrow T$ loading path. Draw the points with $V_{i}$ as the ordinate and $T_{u i}$ as the abscissa, and the single pile bearing capacity envelope under the $V \longrightarrow T$ loading path is plotted by connecting the above points in sequence. A similar method can be used to obtain the single pile bearing capacity envelope under the $T \longrightarrow V$ loading path.

\section{Method Validation}

Since the calculation theory proposed in this article is based on the calculation approach of a single-loaded pile; to confirm the correctness, the calculation results of the singleloaded pile are verified first, and then the calculation method of the $V$-T combined loaded pile is verified.

3.1. Verification of the Calculation Results of a Single Loaded Pile. Harris and Mayne [22] conducted a single pile axial compression test on the Georgia Institute of Technology campus in Atlanta. The soils are primarily the product of the in-place weathering of schists, gneisses, and granites. The stratum was composed of $1.6 \mathrm{~m}$ fill and $16.9 \mathrm{~m}$ silt sand and the water level was $17.0 \mathrm{~m}$ below the surface, as shown in Figure 4 [23]. Consolidation undrained triaxial compression tests were carried out on samples of different depths, and the results show that the value of $c$ and $\varphi$ was relatively constant within the range of pile length, which were 0 and $36.1^{\circ}$, respectively; and the bulk density of the fill and silt sand were both assumed to be $21 \mathrm{kN} / \mathrm{m}^{3}$ by Zhu and Chang [23]. The pile length and pile diameters were $16.8 \mathrm{~m}$ and $0.76 \mathrm{~m}$, respectively, and the elastic modulus of the pile was assumed $20 \mathrm{GPa}$ by Harris and Mayne [22]. The comparison of the vertical load-settlement correlation curve of the pile top ( $V$ $w_{t}$ curve) in the double-layered soils is given in Figure 5. Obviously, the calculation results in this article are closer to the field test data than those of Zhu and Chang [23].

A torsion test on the backfill concrete in the steel pipe pile was conducted by Stoll [24]. Pile-3 had an outer diameter of $0.273 \mathrm{~m}$ with a wall thickness of $6.3 \mathrm{~mm}$, a length of $17.4 \mathrm{~m}$, and a pile body torsional rigidity of $12.8 \mathrm{MN} \cdot \mathrm{m}^{2}$. Zou et al. [25] assumed that the shear modulus of soil was distributed in an exponential function $\left(\tau_{f}=G_{t} e^{m z}\right)$ as a function of the depth and obtained the relevant calculation parameters $\left(G_{t}=5.07 \mathrm{kPa}, m=0.1\right)$ for determining the soil limit friction resistance based on the parametric inversion method and established the theory of this article to obtain the comparison curve of the pile top torque $T$ and torsion angle ( $T-\theta_{t}$ curve) by substituting the above parameters into the calculation theory in this article, as shown in Figure 6. The calculated result of Zou et al. [25] is less than the measured value, while the torsion angle of the pile top calculated in this study is close to Basack and Sen [9], Guo and Randolph [26], and all are larger than the measured value. Guo and Randolph [26] pointed out that with the increase of the torque load, the cracking of the concrete causes the change of the pile body torsional stiffness, which is a possible reason for the inconsistency between the theoretical value and the observed value; in addition, the inability of the load transfer function to fully reflect the characteristics of the foundation is another possible reason for this result.

3.2. Verification of the Calculation Results under the $T \longrightarrow V$ Loading Path. Georgiadis and Saflekou [11] used aluminium alloy pipe piles to conduct four groups of single pile model tests under the $T \longrightarrow V$ loading path in clay soil. The pile length was $0.5 \mathrm{~m}$, the pile diameter was $0.019 \mathrm{~mm}$, and the undrained shear strength of the soil was $8 \mathrm{kPa}$. Figure 7 shows the calculation results in this study of the $T \longrightarrow V$ loading path compared with experimental data and those 


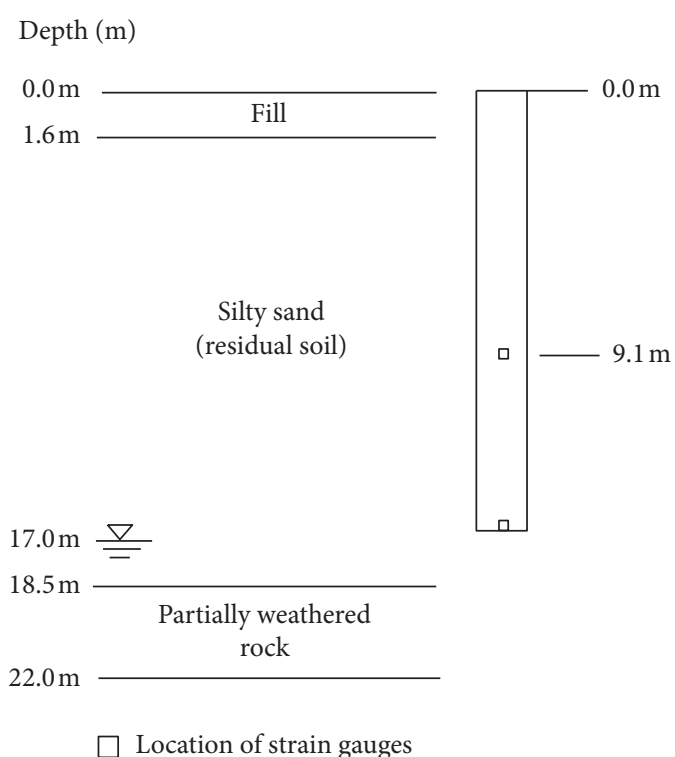

Figure 4: Pile and soil system.

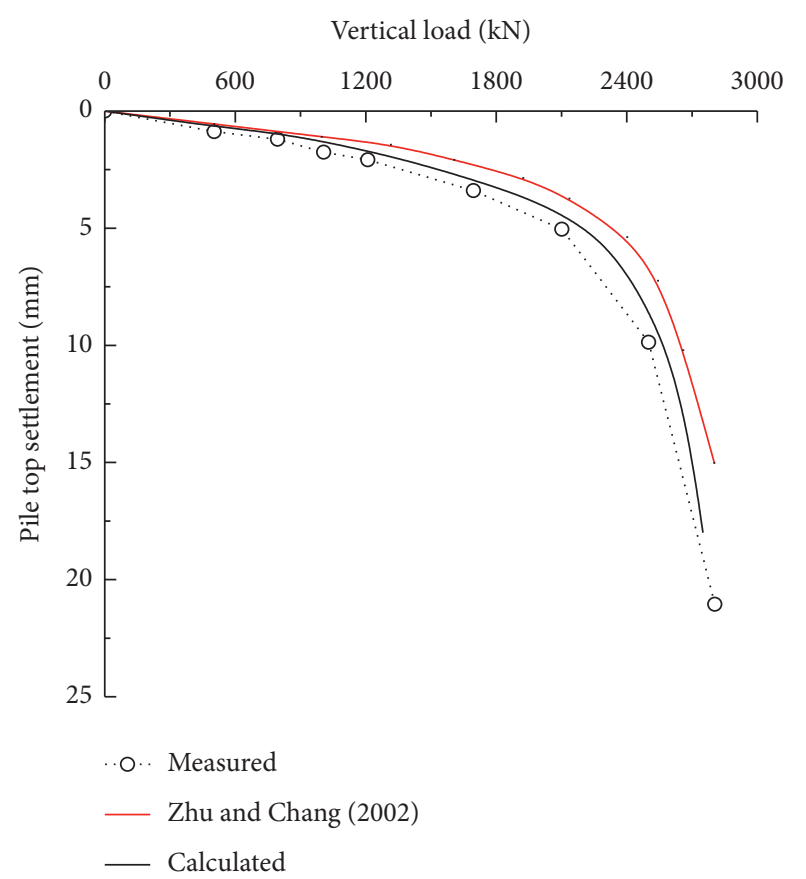

Figure 5: Comparison of the vertical force and settlement of the single pile.

calculated by Georgiadis and Saflekou [11] and Zou et al. [14], and the four sets of experimental data have a large dispersion. In comparison, the calculation results in this study are within these two predicted results and closer to the test results, indicating that the calculation method in this study is more accurate.

3.3. Verification of the Calculation Results under the $V \longrightarrow T$ Loading Path. Georgiadis [10] simulated the relationship of the interface between the pile and soil by utilizing interacting

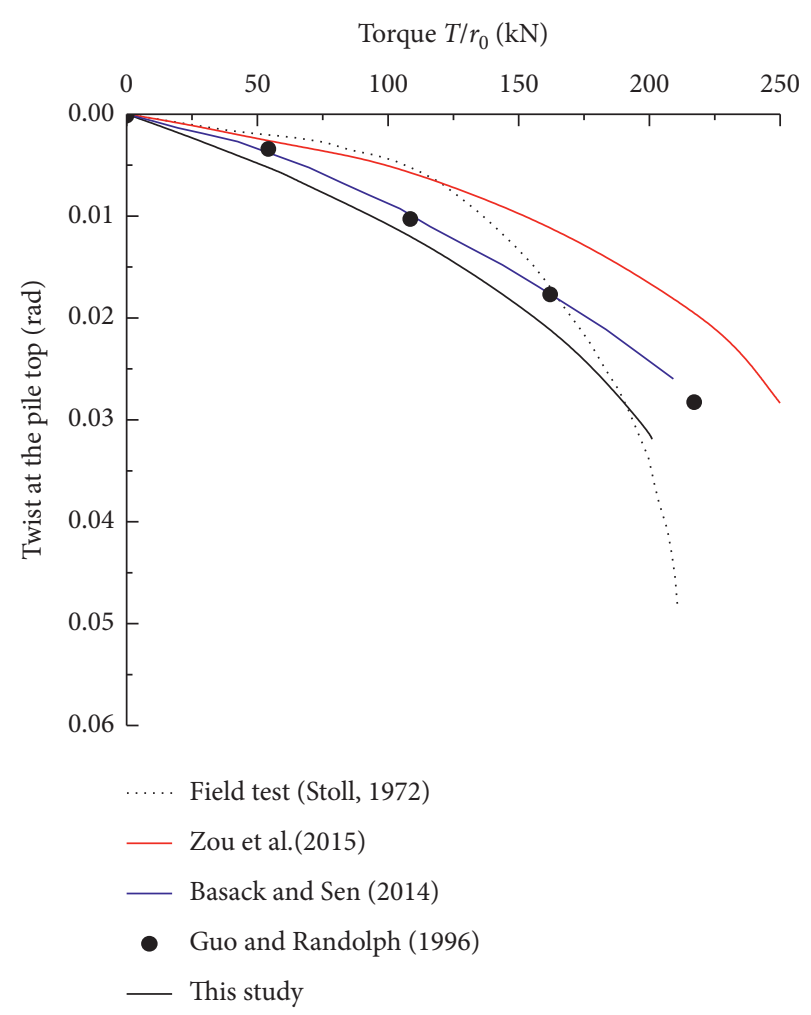

FIGURE 6: Comparison of the torsion and pile top torsion angle of a single pile.

nonlinear axial and torsional springs, compiled a calculation program on the strength of the transfer matrix method, and obtained the nonlinear solution under single pile stress of the $V \longrightarrow T$ loading path by combining with an engineering instance. The calculation parameters of the pile are $D=1.52 \mathrm{~m}, L=50 \mathrm{~m}, E_{p}=20 \mathrm{GPa}, \tau_{f}=50 \mathrm{kPa}$, and the shear modulus of the clay is $5 \mathrm{MN} / \mathrm{m}^{2}$. The vertical load of $100 \mathrm{t}$ was applied to the pile head at first; however, the torque was applied step by step. Comparing the $T-\theta_{t}$ curve calculated with those of Georgiadis [10] and Zou et al. [15], as shown in Figure 8, there is a certain error when the load is less than $6000 \mathrm{kN}$ due to different load transfer functions, while the trend of the curve is consistent with the torque limit, which further verifies the correctness of the calculation method proposed in this article.

\section{Parameter Analysis}

To discuss the main load-bearing characteristics, deformation law and affecting factors of $V$-T combined loaded piles, combined with the theoretical calculation method proposed in this article, the load-bearing characteristics, aspect ratio, and elastic modulus of the pile were analyzed.

4.1. Influence of the Length-Diameter Ratio. The undrained shear strength of the clay is $39.6 \mathrm{kPa}$ and the internal friction angle and elastic moduli are $18^{\circ}$ and $15 \mathrm{MPa}$, respectively, and the elastic modulus of the pile body is $25 \mathrm{GPa}$. Table 1 shows the calculation parameters of pile length and 


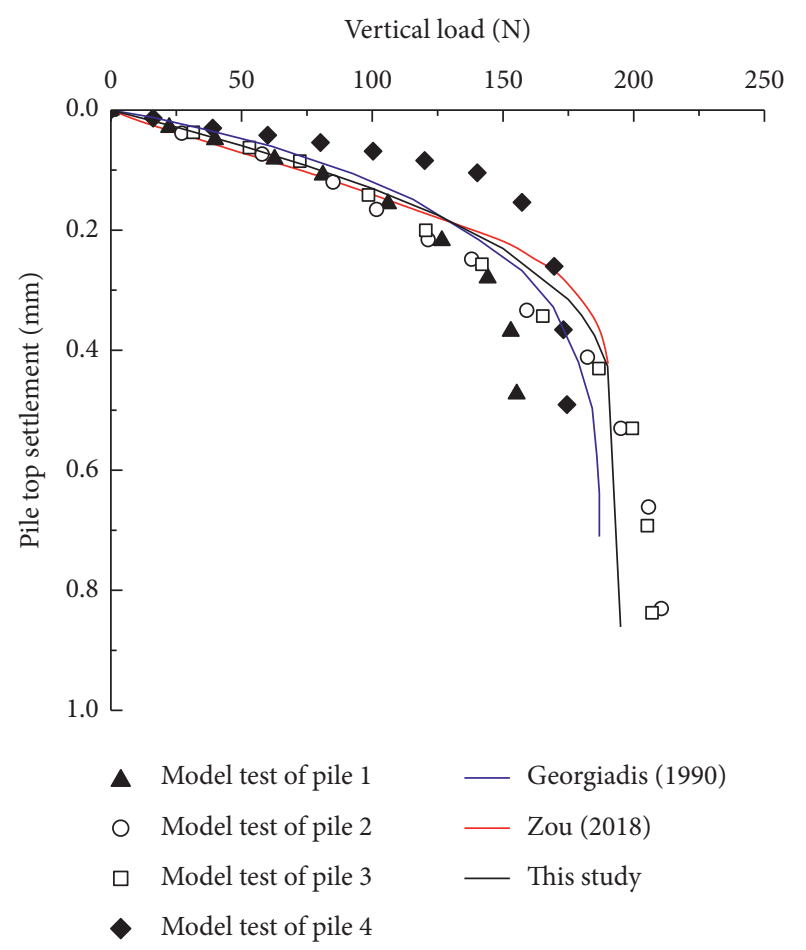

Figure 7: Comparison of the vertical force and settlement of the pile top under the $T \longrightarrow V$ loading path.

diameter. With different pile lengths and diameters, the envelopment of the bearing capacity of a single pile under two loading paths are shown in Figures 9(a) and 9(b). By comparison, it can be found that with increasing pile length and diameter, the bearing capacity envelope of single piles will expand outward, and when the length-diameter ratio is relatively small, two different kinds of bearing capacity envelopes almost coincide. However, with increasing slenderness ratio, the bearing capacity envelope gradually separated, but the $V \longrightarrow T$ bearing capacity envelope was always outside the $T \longrightarrow V$ bearing capacity envelope. Therefore, when the slenderness ratio is relatively small, the effect of the loading path on the bearing capacity of single piles can be ignored. Inversely, when the length-diameter ratio is relatively large, it is necessary to try to avoid the single piles subjected to a torque in advance to prevent the reduction in the ultimate bearing capacity induced by the formation of the $T \longrightarrow V$ loading mode.

4.2. Characteristics of the Pile Displacement. To investigate the displacement of the pile shaft, it is rational to take $T / T_{u}=1 / 2$ and $V / V_{u}=2 / 3$ as the $T \longrightarrow V$ loading path and $V / V_{u}=1 / 2$ and $T / T_{u}=2 / 3$ as the $V \longrightarrow T$ loading path. The lengths of the pile are $48 \mathrm{~m}, 32 \mathrm{~m}, 24 \mathrm{~m}$, and $16 \mathrm{~m}$, the diameter of the pile is $0.8 \mathrm{~m}$, and the elastic modulus of the pile body is $25 \mathrm{GPa}$, and the calculation parameters of the soil are the same to those shown in Section 4.1. The displacement of the pile shaft is shown in Figures 10(a) and 10(b). As illustrated in the figure, when $V / V_{u}$ is a constant value under the $T \longrightarrow V$ loading path and $T / T_{u}$ is a constant value under the $V \longrightarrow T$ loading path, the displacement of the pile shaft is larger when $z / L$ is less than 0.6 ,

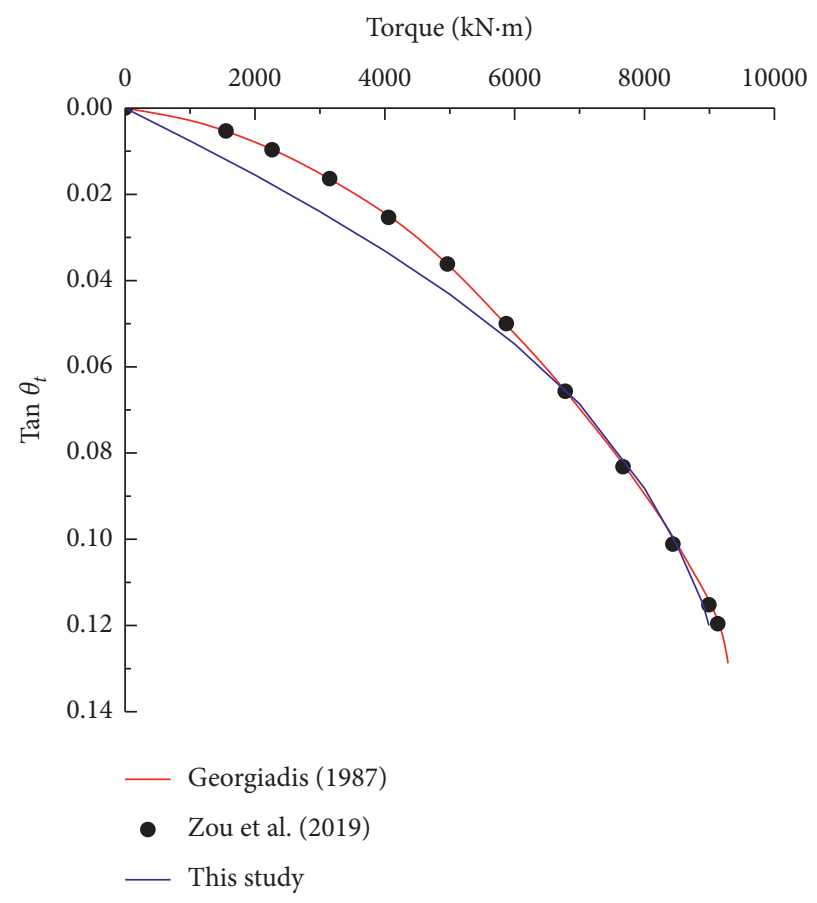

FIgURE 8: Comparison of the torsion angles of the pile top torque under the $V \longrightarrow T$ loading path.

and the displacement is basically stable below a depth of $0.6 \mathrm{~L}$. Therefore, the displacement of the $V$ - $T$ combination loaded pile mainly occurs above the pile body at a depth of $0 \sim 0.6 \mathrm{~L}$. It is reasonable to pay attention to the protection of the shallow foundation to avoid the damage caused by the disturbance. In addition, strengthening the shallow foundation is an effective way to prevent excessive deformation of the pile foundation.

4.3. Influence of the Elastic Modulus of the Pile. To study the influence of the elastic modulus of the pile body on the bearing capacity of the $V-T$ combined loaded pile, take the pile length is $16 \mathrm{~m}$, the pile diameter is $0.8 \mathrm{~m}$, and the calculation parameters of the soil are the same as those shown in Section 4.1. In addition, the elastic modulus of the pile body is $2.5 \mathrm{GPa}, 10 \mathrm{GPa}, 17.5 \mathrm{GPa}$, and $25 \mathrm{GPa}$. The torque is $630 \mathrm{kN} \cdot \mathrm{m}$ under the $T \longrightarrow V$ loading path, and the vertical load is $1600 \mathrm{kN}$ under the $V \longrightarrow T$ loading path. The loaddisplacement curve of a single pile is shown in Figure 11. The ultimate bearing capacity of a single pile under the $T \longrightarrow V$ loading path increases with an increasing elastic modulus of the pile body, as shown in Figure 11(a). However, taking $E_{p}=2.5 \mathrm{GPa}$ and $E p=25 \mathrm{GPa}$ as examples, when the elastic modulus of the pile body increases by 10 times, the vertical bearing capacity barely increases from $1425 \mathrm{kN}$ to $1720 \mathrm{kN}$ at a rate of $17.5 \%$. It is obvious from Figure 11(b) that with increasing elastic modulus of the pile body, the bearing capacity of the single pile under the $V \longrightarrow T$ loading path hardly changes. Consequently, in the actual engineering under $V$-T combined loads, the means is not to increase the concrete grade but to adjust the length-diameter ratio or strengthen the foundation to improve the bearing capacity of the pile-soil system. 
TABLE 1: Table of the calculation parameters for Figures 9(a) and 9(b).

\begin{tabular}{cccccc}
\hline & $\begin{array}{c}\text { Figure 9(a) } \\
\text { Diameter }(\mathrm{m})\end{array}$ & Length $(\mathrm{m})$ & Length-diameter ratio & Length $(\mathrm{m})$ & \multicolumn{2}{c}{ Figure $9(\mathrm{~b})$} \\
& 48 & 60 & & 0.5 & 32 \\
0.8 & 32 & 40 & 16 & 0.8 & 20 \\
& 24 & 30 & & 1.2 & 13.3 \\
& 16 & 20 & 1.6 & 10 \\
\hline
\end{tabular}

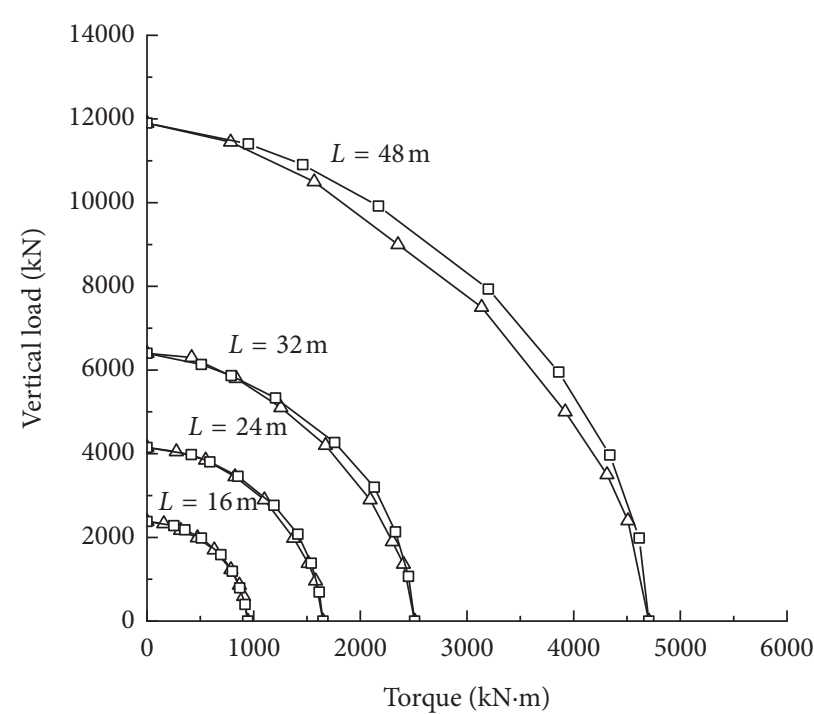

$$
\triangle T \rightarrow V
$$$$
\rightarrow-V \rightarrow T
$$

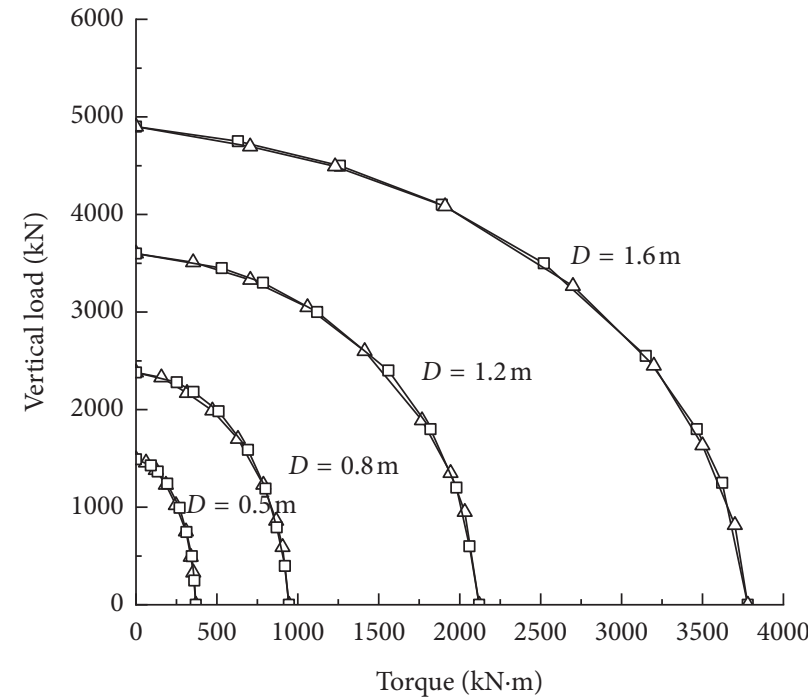

$\rightarrow-V \rightarrow T$

$\triangle \rightarrow \rightarrow V$

(a)

(b)

Figure 9: Effect of the pile length and diameter on the envelope of the single pile bearing capacity. (a) Influence of the pile length. (b) Influence of the pile diameter.

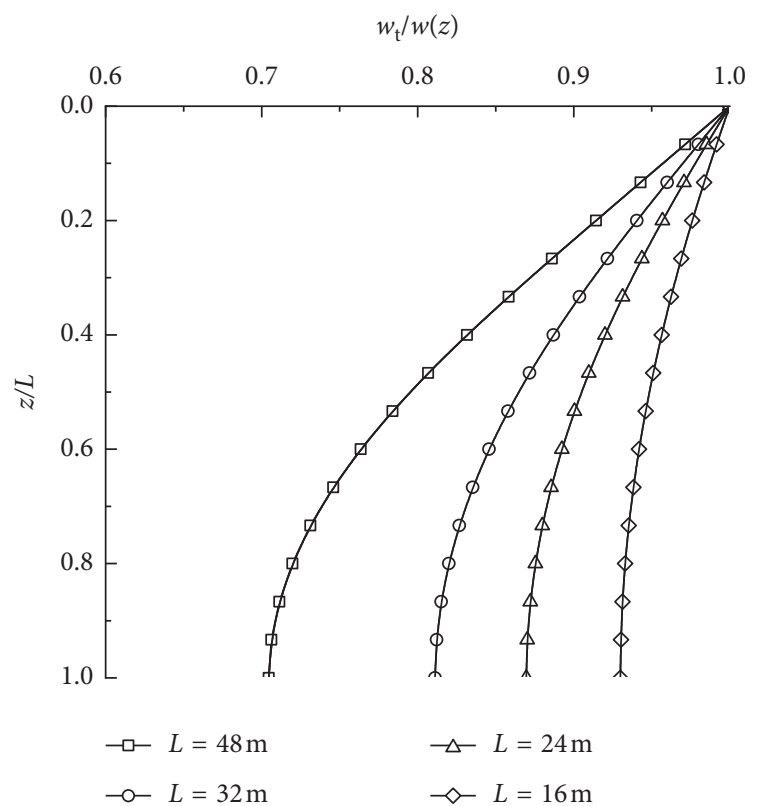

(a)

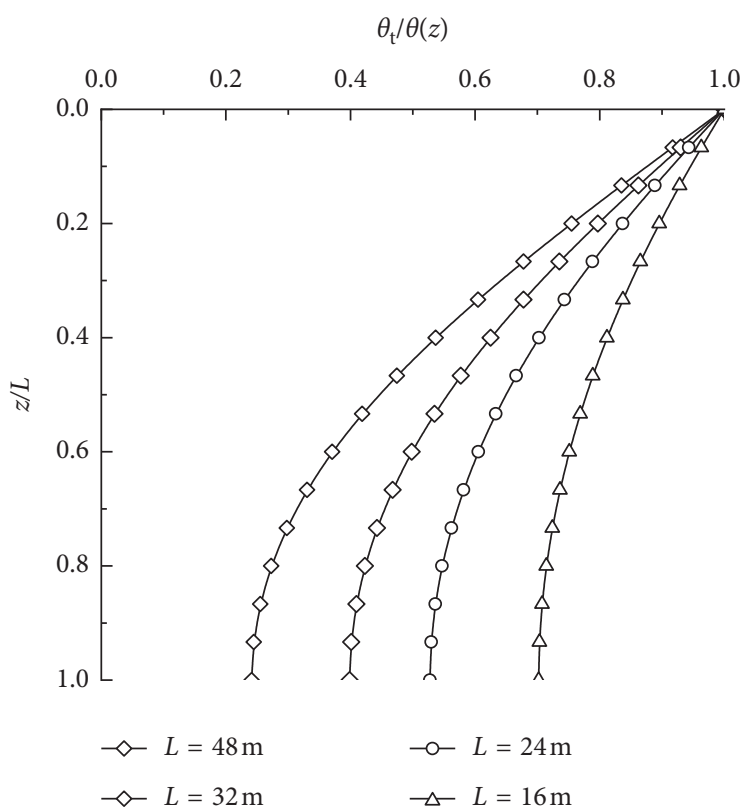

(b)

Figure 10: Influence of L/D on the pile shaft displacement. (a) Settlement of the pile body under the $T \longrightarrow V$ loading path. (b) Torsion angle of the pile body under the $V \longrightarrow T$ loading path. 


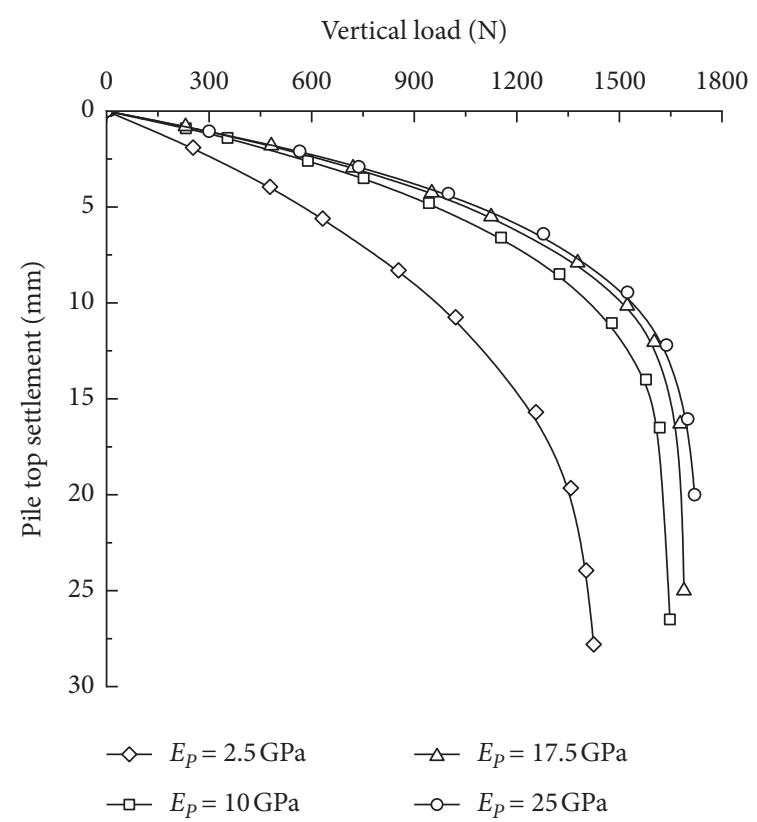

(a)

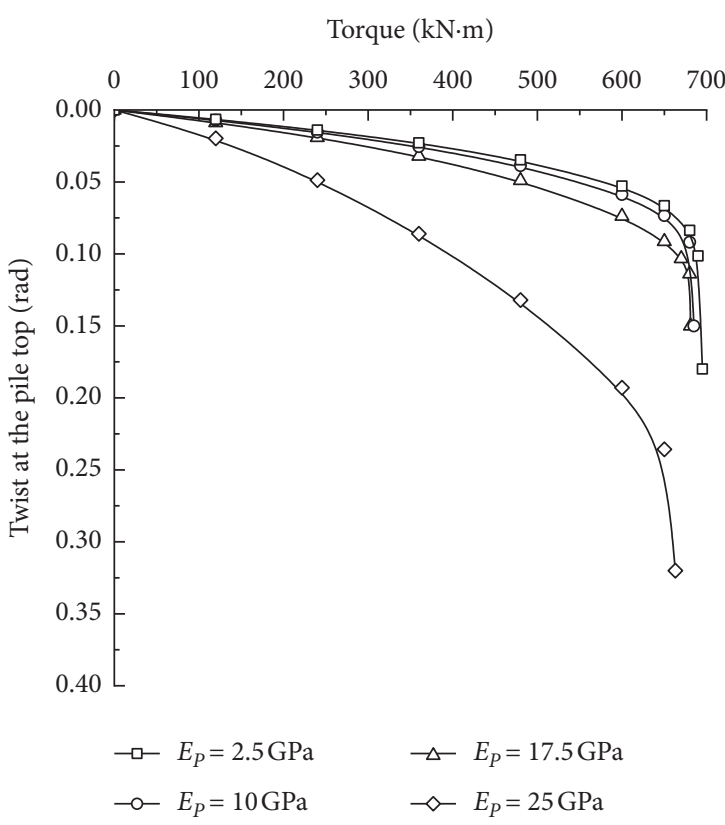

(b)

Figure 11: Influence of the pile elastic modulus on the bearing capacity of a single pile. (a) $V-w_{t}$ curve of a single pile under the $V \longrightarrow T$ loading path. (b) $\mathrm{T}-\theta_{\mathbf{t}}$ curve of a single pile under the $V \longrightarrow T$ loading path.

\section{Conclusion}

Considering different loading paths, the pile bearing characteristics of the $V$-T composite loaded pile were explored through theoretical analysis. The main conclusions are summarized as follows:

(1) The numerical solution of a single loaded pile was obtained by the finite difference method, and considering the influence of different loading paths, a new numerical analysis model was proposed to achieve the numerical solution of single piles under $V$-T combined loading. Compared with the existing research results, the correctness of the calculation model was verified.

(2) Under the combination of $V$-T loading, the bearing capacity of a single pile is lower than that of a single loaded ( $V$ or $T$ ) pile, and the bearing capacity envelope of the $V \longrightarrow T$ loading path is outside the $T \longrightarrow V$ loading path, hence, the former can bear a larger combined $V$ - $T$ load.

(3) Increasing the length and diameter can effectively improve the ultimate bearing capacity of a single pile; when the length-diameter ratio is relatively small, the influence of the loading path can be ignored. However, when the length-diameter is relatively large, the scenario that a single pile is subjected to the pretorque should be avoided to prevent the decrease of the ultimate bearing capacity induced by the formation of the $T \longrightarrow V$ loading mode; the pile body has a larger displacement at a depth of $0-0.6 \mathrm{~L}$, so it is effective to protect or strengthen the shallow foundation to reduce deformation.
(4) Under the $V \longrightarrow T$ loading path, the influence of the pile elastic modulus on the ultimate torque is minimal; as the elastic modulus increases, the vertical ultimate bearing capacity increases under the loading path of $T \longrightarrow V$. However, when the elastic modulus increases by 10 times, the vertical ultimate bearing capacity only increases by $17.5 \%$. Therefore, it is not appropriate to enhance the ultimate bearing capacity of the pile-soil system by increasing the concrete grade.

\section{Abbreviations}

$A_{p}: \quad$ Cross-sectional area of the pile

$B_{i}: \quad$ Calculation parameter

$c: \quad$ Cohesion of the soil

D: $\quad$ Diameter of the pile

$E_{p}$ : $\quad$ Elastic modulus of the pile

$F_{z}^{i}$ : $\quad$ Vertical load vector of the pile node

$G_{L}, G_{P}$, and $G_{s}$ : Shear modulus

$h$ : $\quad$ Length of pile unit

$J_{p}: \quad$ Polar moment of inertia of pile section

$k_{0}$ : $\quad$ Coefficient of the active Earth pressure

$K_{b z}$ : Initial stiffness of the soil at the pile tip

$\left[K_{t}^{\prime}\right]$ : Torsional stiffness matrix of the pile

$\left[K_{z}^{\prime}\right]$ : $\quad$ Vertical stiffness matrix of the pile

$k_{v}$ and $k_{v}^{\prime}$ : Vertical tangent stiffness

$k_{\theta}(z): \quad$ Torsional tangent stiffness

$N_{c}$ and $N_{q}$ : Dimensionless bearing capacity constants

L: $\quad$ Pile length

$n: \quad \quad$ Number of pile elements

$P_{0}$ : $\quad$ Vertical load on pile top

$P(z): \quad$ Axial force of the single pile 
$q$ :

$q_{u l t}:$

$r_{0}:$

$R_{f}$ :

$r_{m}:$

$s_{t}(z):$

$T_{b}$ :

$\left\{T_{t}^{\prime}\right\}$ :

$T(z)$ :

$U_{p}:$

$v_{s}:$

$\{w\}$ :

$w_{0}:$

$w(z):$

$w_{i}$ :

$z:$

$\alpha:$

$\gamma:$

$\theta_{i}:$

$\theta(z)$

$\{\theta\}:$

$\tau_{t}(z)$ :

$\tau_{v}(z):$

$\tau_{t}(i), \tau_{i}$, and

$\tau_{v}(i)$ :

$\tau_{f}(i), \tau_{v f}(i)$, and Ultimate friction force

$\tau_{t f}(i):$

$\varphi$ :

$\varphi^{\prime}:$

\section{Data Availability}

The data, models, or codes generated or used during the study are available from the corresponding author by request.

\section{Conflicts of Interest}

The authors declare that they have no conflicts of interest.

\section{Acknowledgments}

This research was supported by the National Natural Science Foundation of China (Grant nos. 52068004 and 51978179), Natural Science Foundation of Guangxi Province (Grant no. 2018JJA160134), and Guangxi Key Research and Development Program (Grant no. AB19245018).

\section{References}

[1] B. J. Vickery, "Wind effects on building and structures-critical unresolved problems," in Proceeding of IAHR/IUTAM
Practical Experiences with Flow-Induced Vibrations Symposium, pp. 823-828, Karlsrube, Germany, September 1979.

[2] H. B. Seed and L. C. Reese, "The action of soft clay along friction piles," Transactions of the American Society of Civil Engineers, vol. 122, pp. 731-754, 1957.

[3] Q. Q. Zhang, Z.-M. Zhang, and J.-Y. He, "A simplified approach for settlement analysis of single pile and pile groups considering interaction between identical piles in multilayered soils," Computers and Geotechnics, vol. 37, no. 7-8, pp. 969-976, 2010.

[4] J. Jiang, M. S. Huang, and Q. Y. Gu, "Analysis of settlements of vertically loaded pile groups in non-homogeneous soil," Rock and Soil Mechanics, vol. 29, no. 8, pp. 2092-2096, 2008, in Chinese.

[5] H. G. Poulos, "Torsional response of piles," Journal of the Geotechnical Engineering Division, vol. 101, no. 10, pp. 1019-1035, 1975.

[6] M. F. Randolph, "Piles subjected to torsion," Journal of the Geotechnical Engineering Division, vol. 107, no. 8, pp. 1095$1111,1981$.

[7] S. L. Chen and L. M. Zhang, "Torsional response of single pile embedded in layered ground," Journal of Geotechnical Engineering, vol. 27, no. 5, pp. 531-535, 2005, in Chinese.

[8] Q. Li and W. S. Armin, "Simulation of torsionally loaded deep foundations considering state-dependent load transfer," Journal of Geotechnical and Geoenvironmental Engineering, vol. 144, no. 8, 2018.

[9] S. Basack and S. Sen, "Numerical solution of single piles subjected to pure torsion," Journal of Geotechnical and Geoenvironmental Engineering, vol. 140, no. 1, pp. 74-90, 2014.

[10] M. Georgiadis, "Interaction between torsional and axial pile responses," International Journal for Numerical and Analytical Methods in Geomechanics, vol. 11, no. 6, pp. 645-650, 1987.

[11] M. Georgiadis and S. Saflekou, "Piles under axial and torsional loads," Computers and Geotechnics, vol. 9, no. 4, pp. 291-305, 1990.

[12] Q. L. Fan and X. B. Meng, "Failure envelope of pipe pile foundation under combined loading," Advances in Pile Foundations, Geosynthetics, Geoinvestigations, and Foundation Failure Analysis and Repairs, vol. 220, pp. 109-115, Geotechnical Special Publication, Reston, America, 2011.

[13] G. Militano and R. K. N. D. Rajapakse, "Dynamic response of a pile in a multi-layered soil to transient torsional and axial loading," Géotechnique, vol. 49, no. 1, pp. 91-109, 1999.

[14] X. J. Zou, H. T. Du, and Y. X. Wang, "Bearing behavior of a single pile in double-layered nonhomogeneous subsoil under $V$-T combined loads," Chinese Journal of Geotechnical Engineering, vol. 40, no. 10, pp. 1843-1851, 2018, in Chinese.

[15] X. J. Zou, H. T. Du, M. Zhou, and X. Zhou, "Analysis of a single pile under vertical and torsional combined loads in two-layered nonhomogeneous soil," International Journal of Geomechanics, vol. 19, no. 6, p. 15, 2019.

[16] J. G. Potyondy, "Skin friction between various soils and construction materials," Géotechnique, vol. 11, no. 4, pp. 339-353, 1961.

[17] H. G. Poulos and E. H. Davis, Pile Foundation Analysis and Design, John Wiley and Sons, New York, USA, 1980.

[18] L. M. Kraft, R. P. Ray, and T. Kagawa, "Theoretical t-z curves," Journal of the Geotechnical Engineering Division, vol. 107, no. 11, pp. 1543-1561, 1981.

[19] M. F. Randolph and C. P. Wroth, "Analysis of deformation of vertically loaded piles," Journal of the Geotechnical Engineering Division, vol. 104, no. 12, pp. 1465-1488, 1978. 
[20] G. Mylonakis and G. Gazetas, "Settlement and additional internal forces of grouped piles in layered soil," Géotechnique, vol. 48, no. 1, pp. 55-72, 1998.

[21] A. S. Vesic, "Ultimate loads and settlements of deep foundations in sand," in Proceedings of the Symposium on Bearing Capacity and Settlement of Foundation, pp. 53-68, Durham, North Carolina, 1967.

[22] E. Harris and P. Mayne, "Axial compression behavior of two drilled shafts in piedmont residual soils," in Proceedings of the International Conference on Design and Construction of Deep Foundation, pp. 352-367, Washington, D.C, USA, 1994.

[23] H. Zhu and M.-F. Chang, "Load transfer curves along bored piles considering modulus degradation," Journal of Geotechnical and Geoenvironmental Engineering, vol. 128, no. 9, pp. 764-774, 2002.

[24] U. W. Stoll, "Torque shear test of cylindrical friction piles," International Journal of Civil Engineering, vol. 42, no. 4, pp. 63-65, 1972.

[25] X. J. Zou, D. B. Xu, Y. X. Wang, and M. Zhoa, “Torsional elasto-plastic analysis of single piles in heterogeneous ground," International Journal of Civil Engineering, vol. 48, no. 11, pp. 103-110, 2015.

[26] W. D. Guo and M. F. Randolph, "Torsional piles in nonhomogeneous media," Computers and Geotechnics, vol. 19, no. 4, pp. 265-287, 1996. 